\title{
Evaluation of maternal and fetal outcome in corona positive pregnant women
}

\author{
Bharti Maheshwari $^{1}$, Preeti Sharma ${ }^{1 *}$, Kamini Panwar ${ }^{1}$, Kirti Giri Goswami
}

\begin{abstract}
${ }^{1}$ Department of Obstetrics and Gynecology, ${ }^{2}$ Department of Radiodiagnosis, Muzaffarnagar Medical College, Muzaffarnagar, Uttar Pradesh, India
\end{abstract}

Received: 27 September 2020

Revised: 10 November 2020

Accepted: 11 November 2020

\author{
*Correspondence: \\ Dr. Preeti Sharma \\ E-mail: drpreetisharma.sharma@gmail.com
}

Copyright: (C) the author(s), publisher and licensee Medip Academy. This is an open-access article distributed under the terms of the Creative Commons Attribution Non-Commercial License, which permits unrestricted non-commercial use, distribution, and reproduction in any medium, provided the original work is properly cited.

\begin{abstract}
Background: COVID-19 has spread globally at an accelerated rate with rapid increases in cases and mortality. Viral pneumonia is one of the leading causes of pregnancy deaths worldwide. Physiological changes during pregnancy, such as reduced functional residual volumes, diaphragm elevation, and oedema of respiratory tract mucosa, as well as changes in cell immunity can lead to increased susceptibility to viral infections and can have worsened outcomes.

Methods: The study was conducted after clearance from Board of Studies and Ethical committee in the Department of obstetrics and gynaecology, Muzaffarnagar medical college, Muzaffarnagar. It was a retrospective study. Out of total 1500 covid positive patients admitted in 3 months, 33 pregnant women were included which were covid positive. Results: The study population consisted of 16 (48.5\%) women from 20-25 years, 12 (36.4\%) women from 26-30 years and $5(15.2 \%)$ women from above 30 years. There was history of exposure among all (100.0\%) pregnant women with only $2(6.1 \%)$ having symptoms of COVID-19.Out of 33, 8 patients were severelyanemic, 4 had preeclampsia, 2 cases had previous 2 LSCS, 5 previous 1 LSCS, 1 leaking pervaginum, 3 cases had fetal distress at admission. As per gestational age, 9 (27.3\%) women had pre-term delivery, $21(63.6 \%)$ had normal term delivery and $3(9.1 \%)$ had post-term delivery. 13 women were primigravida and 20 were multigravida. The mode of delivery was LSCS among 24 (73\%) and normal delivery among 1 (3.0\%) women.
\end{abstract}

Conclusions: In our study, there were no maternal and fetal complications among pregnant women with COVID-19.

Keywords: COVID-19, Infants, Perinatal transmission, Pregnant women

\section{INTRODUCTION}

The current coronavirus disease 2019 (COVID-19) pneumonia pandemic, which is due to the severe acute respiratory syndrome coronavirus 2 (SARS-CoV-2), has proven to be threat across the globe. First identified in Wuhan, China, in December 2019, COVID-19 has become a pandemic at a rapid pace with high chances of cases and mortality. ${ }^{1,2}$

The major cause for death during the pregnancy across the world is Viral pneumonia. ${ }^{3}$ During pregnancy, there are certain physiological changes, like decrease in the functional residual volumes, rise of the diaphragm, and respiratory tract mucosa having oedema, along with cell immunity modifications causes the susceptibility for more chances for viral infections leading to the worst possible outcomes. ${ }^{4}$

The severe complications were reported among $8 \%$ pregnant women in China which had COVID-19.5 There have been concerns about caesarean deliveries being high $(>90 \%)$ as per the Chinese reports, and not much information is available on the mode of delivery affecting the maternal complications or neonatal transmission. ${ }^{6,7}$ 
Most commonly reported infections during the pregnancy is viral pneumonia, and linked to the maternal and neonatal morbidity and mortality. ${ }^{8}$ Atypical form of pneumonia caused by COVID-19 has been reported to be highly infectious and spreading at a fast pace across the world. ${ }^{9}$ Many studies which focussed on the infected individuals have reported but despite that, information is very scarce related to the pregnancy outcomes among women having COVID-19 infection. Chen et al reported the maternal-neonatal outcomes along with chances for the vertical transmission of COVID-19 pneumonia among pregnant women during the $3^{\text {rd }}$ trimester of pregnancy having an infection with maximum of 7 days. $^{10}$

The immunological and physiological changes which are part of the pregnancy causes the respiratory infections to worsen because of the impact on the systemic effects of the body. High heart rate, oxygen consumption, stroke volume, and reduction in the lung capacity and functional residual capacity are major physiological changes that affect the cardiovascular and respiratory systems at the time of the pregnancy leading to more chances of the complications due to COVID-19 among pregnant women than non-pregnant population. ${ }^{11,12}$

There is compromised immune response during the pregnancy leading to higher chances for infectious diseases. Also, there are more chances of transmission from mother to fetus which might lead to the higher possibility of the infections among fetuses and neonates. ${ }^{11}$

The clinical, radiological, and laboratory characteristics of COVID-19 pneumonia has been found in many research work as far among the pregnant women. As such, not much scientific proof has shown the chances for the intrauterine transmission occurring vertically among the pregnant women. ${ }^{13-17}$

Very less knowledge regarding the coronavirus and high number of cases the disease which are rising at an alarming rate, relevant information about the disease would be practically shared. ${ }^{18}$ Till now, there is only limited number of case reports and series in this regards. Health policy changes in countries affected by the pandemic, continuously evolving clinical management guidelines and uncertainty about the reliability of the results make the findings of these reports difficult to interpret. $^{19}$

However, to date, there are limited studies pertaining to the outcomes of COVID-19 during pregnancy, differences in clinical course, and the potential risks to the unborn child.

The present study was done to evaluate maternal and neonatal outcome among COVID-19 pregnant women to evaluate of effect of disease on pregnancy and to evaluate safety of health worker with available safety protocols.

\section{METHODS}

The study population included covid positive pregnant women referred to Muzaffarnagar medical college, department of obstetrics and gynaecology for management. The study was conducted after clearance from Board of Studies and Ethical committee in the Department of Obstetrics and Gynaecology, Muzaffarnagar Medical College, Muzaffarnagar.

\section{Study type and study place}

It was a cross-sectional study conducted at Department of Obstetrics and Gynaecology, Muzaffarnagar Medical College, Muzaffarnagar.

\section{Study population}

The study population was selected on the basis of the inclusion and exclusion criteria. Out of total 1500 covid positive patients admitted in 3 months, 33 pregnant women were included. Total number of patients in study was 33 covid positive pregnant women.

\section{Study period}

July to September 2020 (3 months).

\section{Study procedure}

After approval from the Institutional Ethical committee all patients were selected as per inclusion and exclusion criteria. All pregnant women had confirmed covid positive test-RTPCR are included in study. A detailed history, complete physical examination and routine and appropriate investigations were done for all patients.

The parameters which were measured were status of covid, severity of covid disease, symptoms suggestive of covid, age, parity, gestational age, blood investigations, x-ray, mother's condition, mode of delivery, Apgar score, neonatal infection status, post-delivery complication, surgeon exposure time (in minutes) and infection status of health worker, infection prevention measures and treatment given, health worker infection after exposure and preventive measures taken.

\section{Statistical analysis}

The data was entered into the Microsoft excel and the statistical analysis was performed by statistical software SPSS version 21.0. The quantitative (numerical variables) were present in the form of mean and SD and the qualitative (categorical variables) were present in the form of frequency and percentage.

The student t-test was used for comparing the mean values between the 2 groups whereas chi-square test was applied for comparing the frequency. The p-value was considered to be significant when less than 0.05 . 


\section{RESULTS}

The study population consisted of $16(48.5 \%)$ women from $20-25$ years, 12 (36.4\%) women from 26-30 years and $5(15.2 \%)$ women from above 30 years. There was history of exposure among all (100.0\%) pregnant women with only $2(6.1 \%)$ having symptoms of COVID-19 (Table 1). All 33 cases were asymptomatic at time of admission and more than 35 weeks of gestation. Out of 33, 08 patients were severely anaemic, 4 had preeclampsia, 2 cases had previous 2 LSCS, 5 previous LSCS, 1 leaking pervaginum, 3 cases had fetal distress at admission. 8 patients managed conservatively and discharged, 1 delivered normally, rest 24 LSCS were done till date.

Table 1: Age wise distribution of the study population.

\begin{tabular}{|lll|}
\hline Age groups & Number & Percentage \\
\hline 20-25 years & 16 & $48.5 \%$ \\
\hline 26-30 years & 12 & $36.4 \%$ \\
\hline More than 30 years & 5 & $15.2 \%$ \\
\hline Total & 33 & $100.0 \%$ \\
\hline
\end{tabular}

Table 2: Showing history of exposure and COVID symptoms.

\begin{tabular}{|llll|}
\hline \multirow{2}{*}{$\begin{array}{l}\text { History of } \\
\text { exposure }\end{array}$} & Exposure & 33 & $100.0 \%$ \\
\cline { 2 - 4 } $\begin{array}{l}\text { COV exposure } \\
\text { COVID }\end{array}$ & 0 & $0.0 \%$ \\
\cline { 2 - 4 } symptoms & No & 2 & $6.1 \%$ \\
\hline
\end{tabular}

Table 3: Showing the gestational age (in weeks).

\begin{tabular}{|lll|}
\hline Gestational age (in weeks) & Number & Percentage \\
\hline <37 weeks (Pre-term) & 9 & $27.3 \%$ \\
\hline $\mathbf{3 7 - 4 0}$ weeks (normal term) & 21 & $63.6 \%$ \\
\hline Above 40 weeks (post-term) & 3 & $9.1 \%$ \\
\hline
\end{tabular}

As per gestational age, $9(27.3 \%)$ women had pre-term delivery, $21(63.6 \%)$ had normal term delivery and 3 $(9.1 \%)$ had post-term delivery. 13 women were primigravida and 20 were multigravida. The mode of delivery was LSCS among $32(97.0 \%)$ and normal delivery among $1(3.0 \%)$ women. There was no postoperative LSCS/obstetric complications.

Table 4: showing the distribution of gravida and parity.

\begin{tabular}{|llll|}
\hline Gravida & Number & Parity & Number \\
\hline G1 & 13 & P1 & 7 \\
\hline G2 & 9 & P2 & 8 \\
\hline G3 & 7 & P3 & 2 \\
\hline G4 & 3 & P4 & \\
\hline G5 & 1 & P5 & \\
\hline
\end{tabular}

Though, 4 cases were shifted at L2 level because of breathlessness on $3^{\text {rd }}$ to $5^{\text {th }}$ postoperative day, managed well and recovered. There was 1 mortality among study population, on $3^{\text {rd }}$ postoperative day, suggestive cause of mortality was pulmonary embolism. There were pneumonitis in 6 patients $(18 \%)$ with positive findings in $\mathrm{X}$-ray of chest, rest patients remained asymptomatic. All neonates were corona negative in this study so vertical transmission was 0\%. Apgar score was more than 9 in 20 cases and more than 7 in 4 cases.

Table 6: Distribution of surgeon exposure time and infection after LSCS.

\begin{tabular}{|llll|}
\hline $\begin{array}{l}\text { Surgeon } \\
\text { exposure time }\end{array}$ & Number & Percentage & $\begin{array}{l}\text { Post exposure } \\
\text { infection }\end{array}$ \\
\hline $\begin{array}{l}\text { Less than } 30 \\
\text { minutes }\end{array}$ & 4 & $16.6 \%$ & Nil \\
\hline 30-45 minutes & 18 & $75 \%$ & Nil \\
\hline $\begin{array}{l}\text { More than } 45 \\
\text { minutes }\end{array}$ & 2 & $8.3 \%$ & Nil \\
\hline
\end{tabular}

There was no post-operative complication $(0 \%)$ and no health care staff was infected $(0 \%)$. Our surgeon exposure time in OT remained 20 minutes to 60 minutes in different cases. All cases were given spinal anaesthesia during LSCS. ICMR protocols were followed in medical management and infection prevention practices.

\section{DISCUSSION}

World Health Organisation (WHO) has reported that there is no apparent difference in the risk of developing clinical symptoms between non-pregnant and pregnant women of reproductive age. ${ }^{10,20}$ It seems the latter is also not at a higher risk of developing severe disease. Patients most commonly present with mild symptoms of the infection including fever, cough, fatigue, and shortness of breath; however, some may be asymptomatic. ${ }^{13,14}$ In a retrospective review by Liu et al, acomparison of 59 patients, which included both pregnant and non-pregnant adults, was carried out. ${ }^{21}$ This review reported no significant difference between the various groups regarding the development of the clinical features of SARS-CoV-2.

Pregnant women undergo physiological changes, which lead to altered immune systems. ${ }^{22}$ This does not necessarily make them more susceptible to viral infection; hence, their response to COVID-19 may be similar to any other viral infection. However, due to the modulated immune system, they may experience severe symptoms, albeit there is a low probability of this happening. According to one study, pregnancy itself does not worsen the symptoms experienced, nor the findings on a CT scan of COVID-19 related pneumonia. ${ }^{4}$

Khan et al reported that SARS-CoV-2 infection may lead to the occurrence of neonatal pneumonia and preterm delivery. ${ }^{23}$ The possibility that these complications can be 
linked to other biological processes or intrauterine infections. The focus of this study was to investigate the vertical transmission potential of SARS-CoV-2 infection. Two of the neonates had suspected COVID-19, indicating the possibility for vertical transmission, but there was find no convincing evidence to confirm the vertical transmission potential of SARS-CoV-2. ${ }^{23}$

In the study by Khan et al, neonatal pneumonia occurred in five of the 17 neonates. In 15 neonates, SARS-CoV-2 was not detected in the throat swab. ${ }^{23}$ The swab samples tested within 24 hours after the delivery were positive in only two neonates (case 6 and case 14). However, intrauterine tissue samples such as placenta, cord blood or amniotic fluid were not tested to confirm if the infection in the neonate was the result of intrauterine transmission. Intrauterine vertical transmission was not reported by either Chen et al for COVID-19 (n=9) or Wong et al for SARS $(n=12) .{ }^{10,24}$

Shanes et al examined the placentas of 16 women with severe COVID-19 infection (15 live births in the third trimester and 1 delivered in the second trimester after intrauterine foetal demise). ${ }^{25}$ The study found that pregnant women who were infected with COVID-19 and delivered in the third trimester were more likely to have placentas that show features of maternal vascular malperfusion and intervillous thrombi. These findings suggest abnormal maternal circulation that is associated with adverse perinatal outcomes. These changes may reflect a systemic inflammatory or hypercoagulable state influencing placental physiology. Shanes et al noted that increased antenatal surveillance for women with COVID19 may be warranted..$^{25}$

\section{Gestational age}

In our study, $27.3 \%$ women had pre-term delivery, $63.6 \%$ had normal term delivery and $9.1 \%$ had post-term delivery. Preliminary reviews reported high rates of preterm delivery, ranging from 41 to $47 \% .^{19,26} \mathrm{~A}$ systematic review of 33 studies subsequently described the out-comes of 385 pregnant women with COVID-19 with gestational age at birth ranging from 30 to 41 weeks gestation and a preterm birth rate of $15.2 \% .^{27}$

While many of the preterm deliveries were iatrogenic and for maternal reasons, there are reports of fetal distress as the indication in some cases, although in others the indication for delivery is unclear. ${ }^{27}$ At present, there is insufficient evidence to determine any correlation between spontaneous preterm labour and COVID-19 infection in pregnancy although there are some reported cases of preterm prelabour rupture of membranes. ${ }^{10,26}$

\section{Mode of delivery}

Muhidinetal reported that the preferred mode of delivery was caesarean section and only five women $(6 \%)$ delivered vaginally; none of whose neonates was infected with COVID-19. ${ }^{28}$ Intrapartum transmission was the main concern for choosing cesarean section. Since there is limited evidence about vertical transmission and vaginal shedding of virus, vaginal delivery in stable patients may be considered. In cases of caesarean section, the choice of anaesthesia needs careful consideration. ${ }^{29}$ Favre et al suggested that for every individual patient, vaginal delivery even by induction should be considered. Using instrumental delivery also is preferred to caesarean section to avoid unnecessary surgical complications and maternal exhaustion. ${ }^{30}$

With regard to the mode of delivery, caesarean section was performed in the majority of cases and several authors cited fetal distress as the reason behind the decision. ${ }^{10,15,29}$ Zaigham and Andersson reported that among 7 cases of spontaneous vaginal delivery were not associated with poorer outcomes. ${ }^{19}$ In line with Huang et al, the most common presenting sign was fever and a non-productive cough. ${ }^{1}$ Tiredness, shortness of breath and diarrhea were reported only occasionally. Zaigham and Andersson stated that $21 \%$ pregnancies presented at earlier gestations, and they were all discharged without any serious complications. ${ }^{19}$

Regarding the perinatal outcomes, most authors did not report any adverse events. ${ }^{10,31-36}$ In contrast, Zhu et al, reported one neonatal death and a total of 6 admissions to the neonatal intensive care unit (ICU). ${ }^{13}$ The first symptom in the newborns was shortness of breath, observed in six neonates. Other initial symptoms were fever, thrombocytopenia accompanied by abnormal liver function, tachycardia, vomiting and pneumothorax. In the Zhu et al cohort, six of 10 were neonates born prematurely and eight of 10 were delivered by caesarean section, two factors that may have contributed to the morbidity. ${ }^{13}$

In current study, there was one mortality among study population. Fan et al presented two cases of SARS-CoV2-positive pregnancies. ${ }^{11}$ One term baby developed lowgrade fever and abdominal distension with lymphocytopenia on day 3 and the day after, a chest radiograph revealed diffuse haziness. The baby was discharged 9 days after delivery. The second baby was delivered by caesarean section at $36+5$ weeks gestational age; and went on to develop mild neonatal pneumonia with lymphocytopenia, which was treated with antibiotics. The neonate recovered within 2 days.

Neonates from COVID-19-positive women should be tested, isolated, and cared following droplet and contact preventive measures. ${ }^{37}$ The WHO recommends for mothers with COVID-19 infection to be able to room in with their babies. ${ }^{38}$ The mother should wear a surgical mask and practice hand hygiene when in close contact with her infant, particularly when feeding. Alternatively, if another healthy adult is in the room, they can care for the newborn. Asymptomatic newborns could be 
discharged after delivery and cared by an asymptomatic family member with the adequate isolation measures.

During this extremely delicate time of a rapidly evolving outbreak that has imposed a tremendous threat on public health, more attention should be given to the unique needs of pregnant women. ${ }^{12}$ Further investigation and isolation should be considered for pregnant women with suspected COVID-19. In confirmed cases, prompt admission of mothers in a negative pressure isolation unit is crucial. ${ }^{29}$

All the medical staff responsible for taking care of COVID19 patients should utilize personal protective equipment, namely N95 masks, gloves, gown, and goggles. Standard protocol of the management of COVID-19 in pregnancy incorporates early isolation, controlling infection, administrating oxygen, detecting other viral infections, applying early mechanical ventilation in patients with progressive respiratory failure, and administrating antibiotics in cases of risk of bacterial infection. Monitoring of fetus and uterine contraction should be considered. Any planning on delivery of the patients and their conditions should be made through multispecialty consultations. ${ }^{12}$.

\section{CONCLUSION}

The available data revealed that clinical manifestations of pregnant women in late pregnancy are similar to those of non-pregnant adults. In our study, there were no maternal and fetal complications among pregnant women with COVID-19.

Overall, due to the lack of information on COVID-19 pneumonia in pregnancy, all suspected pregnant women should be systematically screened, monitored and followed up. Another issue is whether natural vaginal delivery increases the likelihood of vertical transmission of the infection and if so, the possible mechanisms need to be clarified. Further investigations and follow-up studies of pregnant mothers infected by COVID-19 are warranted.

Funding: No funding sources Conflict of interest: None declared

Ethical approval: The study was approved by the Institutional Ethics Committee

\section{REFERENCES}

1. Huang C, Wang Y, Li X, Ren L, Zhao J, Hu Y, et al. Clinical features of patients infected with 2019 novel coronavirus in Wuhan, China. Lancet. 2020;395:497506.

2. Abuelgasim E, Saw L, Shirke M, Zeinah M, Harky A. COVID-19: Unique public health issues facing Black, Asian and minority ethnic communities. Curr Prob Cardiol. 2020;45(8):100621.
3. Dashraath P, Jing Lin Jeslyn W, Mei Xian Karen L, Lim ML, Li S, Biswas A, et al. Coronavirus disease 2019 (COVID-19) pandemic and pregnancy. Am J Obstet Gynecol. 2020;222(6):521-31.

4. Liu W, Wang Q, Zhang Q, Chen L, Chen J, Zhang B, et al. Coronavirus disease 2019 (COVID-19) during pregnancy: a case series. Preprints. 2020; 2020020373.

5. Chen L, Li Q, Zheng D, Jiang H, Wei Y, Zou L, et al. Clinical characteristics of pregnant women with Covid-19 in Wuhan, China. $\mathrm{N}$ Engl $\mathrm{J}$ Med. 2020;382:e100.

6. Della Gatta AN, Rizzo R, Pilu G, Simonazzi G. Coronavirus disease 2019 during pregnancy: a systematic review of reported cases. Am J Obstet Gynecol. 2020;223(1):36-41

7. Kimberlin DW, Stagno S. Can SARS-CoV-2 infection be acquired in utero? more definitive evidence is needed. JAMA. 2020;323(18):1788-9.

8. Schwartz DA, Graham AL. Potential maternal and infant outcomes from (Wuhan) coronavirus 2019nCoV infecting pregnant women: lessons from SARS, MERS, and other human coronavirus infections. Viruses 2020;12:1-16.

9. Khan S, Siddique R, Ali A, Xue M, Nabi G. Novel coronavirus, poor quarantine, and the risk of pandemic. J Hosp Infect. 2020;104(4):449-50.

10. Chen H, Guo J, Wang C, Luo F, Yu X, Zhang W, et al. Clinical characteristics and intrauterine vertical transmission potential of COVID-19 infection in nine pregnant women: a retrospective review of medical records. Lancet. 2020;6736:1-7.

11. Fan C, Lei D, Fang C, Li C, Wang M, Liu Y, et al. Perinatal transmission of COVID-19 associated SARS-CoV-2: should we worry? Clin Infect Dis. 2020.

12. Rasmussen SA, Jamieson DJ, Uyeki TM. Effects of influenza on pregnant women and infants. American J Obstet Gynecol. 2012;207(3):S3-8.

13. Zhu H, Wang L, Fang C, Peng S, Zhang L, Chang G, et al. Clinical analysis of 10 neonates born to mothers with 2019-nCov pneumonia. Transl Pediatr. 2020;9:51-60.

14. Liu Y, Chen H, Tang K, Guo Y. Clinical manifestations and outcome of SARS-CoV-2 infection during pregnancy. J Infect. 2020.

15. Zhang L, Jiang Y, Wei M, Chen BH, Zhou XC, Li J, et al. Analysis of the pregnancy outcomes in pregnant women with COVID-19 in Hubei Province. Zhonghua Fu Chan Ke Za Zhi. 2020;55:166.

16. Lei D, Wang C, Li C, Fang C, Yang W, Chang B, et al. Clinical characteristics of COVID-19 in pregnancy: analysis of nine cases. Chin J Perinat Med. 2020;23(03):159-65.

17. Yan J, Guo J, Fan C, Juan J, Yu X, Li J, et al. Coronavirus disease 2019 (COVID-19) in pregnant women: a report based on 116 cases. Am J Obstet Gynecol. 2020;223(1):111.e1-14.

18. Guan WJ, Ni ZY, Hu Y, Liang WH, Ou CQ, He JX, et al. China Medical Treatment Expert Group for 
Covid-19. Clinical characteristics of coronavirus disease 2019 in China. N Engl J Med. 2020;382(18):1708-20.

19. Zaigham M, Andersson O. Maternal and perinatal outcomes with COVID-19: A systematic review of 108 pregnancies. Acta Obstet Gynecol Scand. 2020;99(7):823-9.

20. Aylward B, Liang W, Dong X, Eckmanns T, Fisher D, Ihekweazu C. Report of the WHO China joint mission on coronavirus disease 2019 (COVID-19). Beijing: World Health Organisation; 2020.

21. Liu H, Liu F, Li J, Zhang T, Wang D, Lan W. Clinical and CT imaging features of the COVID-19 pneumonia: focus on pregnant women and children. $\mathrm{J}$ Infect. 2020;80(5):e7-13.

22. Coronavirus (COVID-19) Coronavirus infection in pregnancy. Royal College of Obstetrician and Gynaecologist. 2020. Available from: https://www.rcog.org.uk/globalassets/documents/gui delines/2020-10-14-coronavirus-covid-19-infectionin-pregnancy-v12.pdf. Accessed on 29 April 2020.

23. Khan S, Jun L, Nawsherwan, Siddique R, Li Y, Han $\mathrm{G}$, et al. Association of COVID-19 with pregnancy outcomes in health-care workers and general women. Clin Microbiol Infect. 2020;(26):788-90.

24. Wong SF, Chow KM, Leung TN, Ng WF, Ng TK, Shek CC, et al. Pregnancy and perinatal outcomes of women with severe acute respiratory syndrome. Am J Obstet Gynecol. 2004;191:292-7.

25. Shanes ED, Mithal LB, Otero S, Azad HA, Miller ES, Goldstein JA. Placental pathology in COVID-19. Am J Clin Pathol. 2020;154(1):23-32.

26. Di Mascio D, Khalil A, Saccone G, Rizzo G, Buca $\mathrm{D}$, Liberati $\mathrm{M}$, et al. Outcome of Coronavirus spectrum infections (SARS, MERS, COVID 1-19) during pregnancy: a systematic review and metaanalysis. Am J Obstet Gynecol MFM. 2020:100107.

27. Elshafeey F, Magdi R, Hindi N, Elshebiny M, Farrag $\mathrm{N}$, Mahdy $\mathrm{S}$, et al. A systematic scoping review of COVID-19 during pregnancy and childbirth. Int J Gynecol Obstet. 2020;150(1):47-52.

28. Muhidin S, BehboodiMoghadam Z, Vizheh M. Analysis of maternal coronavirus infections and neonates born to mothers with 2019-nCoV: a systematic review. Arch Acad Emerg Med. 2020;8(1):e49.
29. Liang H, Acharya G. Novel corona virus disease (COVID-19) in pregnancy: What clinical recommendations to follow? Acta Obstet Gynecol Scand. 2020 Apr;99(4):439-42.

30. Favre G, Pomar L, Qi X, Nielsen-Saines K, Musso $\mathrm{D}$, Baud D. Guidelines for pregnant women with suspected SARSCoV-2 infection. Lancet Infect Dis. 2020;S1473-3099(20)30157-2.

31. Li Y, Zhao R, Zheng S, Chen X, Wang J, Sheng X, et al. Lack of vertical transmission of severe acute respiratory syndrome coronavirus 2, China. Emerg Infect Dis. 2020;26(6).

32. Shaoshuai W, Lili G, Ling C, Weiyong L, Yong C, Jingyi Z, et al. A case report of neonatal COVID 19 infection in China. Clin Infect Dis. 2020.

33. Zambrano LI, Fuentes-Barahona IC, Bejarano-Torres DA, Bustillo C, Gonzales G, Vallecillo-Chinchilla G, et al. A pregnant woman with COVID-19 in Central America. Travel Med Infect Dis. 2020;101639.

34. Gidlöf S, Savchenko J, Brune T, Josefsson H. COVID-19 in pregnancy with comorbidities: more liberal testing strategy is needed. Acta Obstet Gynecol Scand. 2020.

35. Breslin N, Baptiste C, Miller R, Fuchs K, Goffman D, Gyamfi-Bannerman C, et al. COVID-19 in pregnancy: early lessons. Am J Obstet Gynecol MFM. 2020; 100111.

36. Iqbal SN, Overcash R, Mokhtari N, Saeed H, Gold S, Auguste $\mathrm{T}$, et al. An uncomplicated delivery in a patient with COVID-19 in the United States. N Engl J Med. 2020;382(16):e34.

37. CDC. Considerations for Inpatient Obstetric Healthcare Settings. Available at: www.cdc.gov/coronavirus/2019-ncov/hcp/inpatientobstetric-healthcare-guidance.html.

38. WHO. Clinical management of severe acute respiratory infection when COVID-19 is suspected. Available at: www.who.int/publicationsdetail/clinical-management-of-severe-acuterespiratory-infection-when-novel-coronavirus(ncov)-infection-is-suspected.

Cite this article as: Maheshwari $\mathrm{B}$, Sharma $\mathrm{P}$, Panwar K, Goswami KG. Evaluation of maternal and fetal outcome in corona positive pregnant women. Int J Reprod Contracept Obstet Gynecol 2020;9:5037-42. 